\title{
Exogenous spermidine enhances salt-stressed rice photosynthetic performance by stabilizing structure and function of chloroplast and thylakoid membranes
}

\author{
D.X. JIANG, X. CHU, M. LI, J.J. HOU, X. TONG, Z.P. GAO ${ }^{+}$, and G.X. CHEN ${ }^{+}$ \\ Jiangsu Key Laboratory of Biodiversity and Biotechnology, Life Sciences College, Nanjing Normal University, \\ 210023 Nanjing, China
}

\begin{abstract}
Spermidine (Spd) is a ubiquitous low-molecular-mass aliphatic amine that acts in abiotic stress tolerance in plants. We investigated how the treatment with exogenous Spd contributed to the protection against salt stress in rice chloroplasts. Analysis of the chlorophyll (Chl) fluorescence showed that there were many negative effects of salinity on different sites of the photosynthetic machinery; however, these were alleviated by adding Spd. Spd prevented the damage of structure and function of chloroplasts under salt stress; thylakoid membrane protein components and photosynthetic pigments were not severely affected by salinity in Spd-treated plants. Spd enhanced the activities of antioxidant enzymes and decreased contents of reactive oxygen species and malondialdehyde accumulation, suggesting that Spd may participate in the redox homeostasis in chloroplasts under salt stress. These results highlighted the positive effects of Spd on rice chloroplasts under salt stress through maintaining chloroplast structure stability.
\end{abstract}

Additional key words: growth regulator; OJIP transient; Oryza sativa; redox balance.

\section{Introduction}

Due to the generation of hyperosmotic effect by reducing the soil water potential, salt stress is one of the most deleterious environmental factors limiting crop growth and yield worldwide (Liu et al. 2008). Salinity causes osmotic stress, free radical production, and nutritional stress, which induces structural damage and a loss of turgidity in plant cells, thereby inhibiting plant normal growth (Munns and Tester 2008, Li et al. 2016). Notably, salinityinduced inhibition of the photosynthetic electron transport results in excessive accumulation of toxic reactive oxygen species (ROS) and damage of membranes through lipid peroxidation. Previous studies have demonstrated that salinity often leads to a decline of photosynthesis in plants (Mittal et al. 2012, Shu et al. 2013). Salt stress causes the damage to semipermeability of the plasma membrane resulting from changes in $\mathrm{K}^{+} / \mathrm{Na}^{+}$ratios, which breaks the interstitial ionic homeostasis. Salt stress induces the inhibition of photosynthesis through stomatal and nonstomatal limitations including stomatal closure, damage of chloroplast structure, loss of photosynthetic pigments, inhibition of carbon assimilation, and degradation of membrane proteins in the photosynthetic apparatus (Mittal et al. 2012, Gil et al. 2013, Shu et al. 2013, Li et al. 2015a). However, stressed plants possess a pool of antioxidant enzymes including superoxide dismutase (SOD), catalase (CAT), ascorbate peroxidase (APX), and glutathione reductase (GR) to prevent accumulation of ROS and hence the damage of lipids, proteins, and DNA (Noctor and Foyer 1998).

Polyamines (PAs), including putrescine (Put), spermidine (Spd), and spermine (Spm), are ubiquitously distributed in living organism, which has been regarded as a new class of growth substances in improving plant stress resistance ability (He et al. 2002, Pál et al. 2015). These three main PAs were found to be closely related to thylakoid membranes and photosynthetic subcomplexes (Kotzabasis et al. 1993). It is well known that PAs act as the stabilizing factors on biomembranes and macromolecules (Watanabe et al. 1991, Navakoudis et al. 2007). Much evidence has shown that application of exogenous PAs can reduce the loss of pigments, inhibit destruction of the thylakoids, and enhance the photosynthetic rate (Besford et al. 1993, Beigbeder et al. 1995). Salinity damage to PSI and PSII activity is also effectively alleviated by the addition of

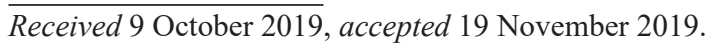

${ }^{+}$Corresponding author; e-mail: guoxiangchenninu@163.com (G.X. Chen), ketty-1982@163.com (Z.P. Gao)

Abbreviations: APX - ascorbate peroxidase; BN-PAGE - blue native-polyacrylamide gel electrophoresis; CAT - catalase; Cyt $b_{6} / f$ cytochrome $b_{6} / f$ complex; DM - n-dodecyl- $\beta$-d-maltoside; DTNB - 5,5'-dithiobis-(2-nitrobenzoic acid); GR - glutathione reductase; $\mathrm{K}_{\mathrm{n}}$ - nonphotochemical rate constant; $\mathrm{K}_{\mathrm{p}}$ - photochemical rate constant; MDA - malondialdehyde; OEC - oxygen-evolving complex; PAs - polyamines; RC - reaction center; ROS - reactive oxygen species; SOD - superoxide dismutase; Spd - spermidine; TBA thiobarbituric acid; TEM - transmission electron microscopy.

Acknowledgements: This work was supported by the Jiangsu Agricultural Science and Technology Independent Innovation Fund (CX173022, CX181001) and Natural Science Foundation of Jiangsu province (BK20171034). 
exogenous PAs through the roots (Chattopadhayay et al. 2002). Additionally, it has been reported that PAs reverse malondialdehyde (MDA) accumulation, scavenge ROS, and enhance the activities of antioxidant enzymes (Igarashi and Kashiwagi 2000, Kuznetsov et al. 2006, Li et al. 2015a). Among the three major forms of PAs, Spd is closely associated with stress tolerance in plants (Kasukabe et al. 2004). Exogenous application of Spd confers short-term salinity tolerance in creeping bentgrass through activating antioxidant enzymes and affecting the activities of enzymes involved in PA metabolism (Li et al. 2015b). Duan et al. (2008) described the improvement of net photosynthetic rate and actual photochemical efficiency of PSII in saltstressed cucumber seedlings treated with Spd. However, Beauchemin et al. (2007) noted that high concentration of Spd was shown to elicit strong inhibitory effects on PSII submembrane fractions of spinach thylakoids, resulting in a decrease of plastoquinone reduction. Exogenous Spd plays vital roles in preventing the electrolyte and amino acid leakage, photosynthetic pigment loss, inhibition of photochemical reactions, or recovering the plasma membrane damage in rice in response to salinity (Chattopadhayay et al. 2002, Roychoudhury et al. 2011).

Chloroplast is the essential organelle of green plants, where photosynthesis takes place and is very sensitive to the changes of external environment (Kaiser et al. 2015). The objective of the present work was to assess the effect of exogenous Spd treatment on the acclimation of rice chloroplast to salt stress. This study was undertaken to test the hypothesis that exogenous Spd acts via the improvement of the antioxidant defense systems in chloroplasts. Spd may play a significant protective role in maintaining the redox balance in chloroplasts and the integrity of photosynthesis apparatus in response to salt stress. The knowledge of the chloroplast adaptive mechanisms induced by Spd helps further reveal how this plant growth regulator provides tolerance against salinity to rice.

\section{Materials and methods}

Plant materials, growth conditions, and experimental design: Seeds of rice cultivars, Oryza sativa L. cv. Nipponbare, were kindly gifted from Prof. Chuangen Lv (Jiangsu Academy of Agricultural Sciences, China). Uniform and healthy seeds of rice were surface-sterilized with $5 \%$ sodium hypochlorite for $30 \mathrm{~min}$ followed by washing several times. The seeds were then placed in Petri plates containing several layers of filter paper moistened with distilled water for germination. The rice seedlings were kept at a plant growth chamber [irradiance of $500 \mu \mathrm{mol}$ (photon) $\mathrm{m}^{-2} \mathrm{~s}^{-1}$; temperature of $30 / 25^{\circ} \mathrm{C}$ day/ night; relative humidity of $80 \%$ ] for $30 \mathrm{~d}$. Hoagland's nutrient solution was applied as nutrient. A preliminary experiment, employing $100 \mathrm{mM} \mathrm{NaCl}$ to simulate moderate salt stress and different Spd concentrations $(0$, $0.2,0.6,1.0,1.5 \mathrm{mM})$ were used as a salt-stress tolerance test. It showed that $1 \mathrm{mM}$ Spd exhibited the best effect on reducing malondialdehyde (MDA) content in the chloroplasts of rice seedlings under salt stress. Four general conditions were used in the experiments:

\begin{tabular}{ll}
\hline Treatment & \\
\hline $\mathrm{CK}$ (control) & Hoagland's nutrient solution $+0 \mathrm{mM} \mathrm{Spd}$ \\
$\mathrm{Spd}$ & $0 \mathrm{mM} \mathrm{NaCl}+1 \mathrm{mM} \mathrm{Spd}$ \\
$\mathrm{NaCl}$ & $100 \mathrm{mM} \mathrm{NaCl}+0 \mathrm{mM} \mathrm{Spd}$ \\
$\mathrm{NaCl}+\mathrm{Spd}$ & $100 \mathrm{mM} \mathrm{NaCl}+1 \mathrm{mM} \mathrm{Spd}$ \\
\hline
\end{tabular}

Hoagland nutrient solution was renewed every $3 \mathrm{~d}$, and the $\mathrm{pH}$ of nutrient solutions was adjusted every day to 6.5 with $0.05 \mathrm{M} \mathrm{HCl}$ or $\mathrm{NaOH}$ supplementation. After 7-d treatment, the fourth fully expanded leaves of each treatment were randomly selected to measure Chl fluorescence parameters, detect chloroplast ultrastructure, and then were frozen in liquid nitrogen immediately after collection and stored at $-80^{\circ} \mathrm{C}$ for other experiments. Treatments were carried out using a completely randomized design with three replications and were analyzed independently.

Photosynthetic pigments: The $\mathrm{Chl} a, \mathrm{Chl} b$, and total Chl concentration were determined according to the method of Lichtenthaler (1987). Chl was extracted from the fourth fully expanded leaves $(100 \mathrm{mg})$ with $80 \%$ acetone in darkness for $24 \mathrm{~h}$ at $25^{\circ} \mathrm{C}$. The concentration of photosynthetic pigment was estimated at 663 and $644 \mathrm{~nm}$ by using a spectrophotometer (GENESYS 10, Thermo Electron, USA).

Chl $\boldsymbol{a}$ fluorescence transient and JIP-test: The Chl $a$ fluorescence induction kinetics was measured at room temperature using a pocket fluorometer (Handy PEA, Hansatech, UK). A typical Chl fluorescence transient shows a sequence of phases from the initial $\left(\mathrm{F}_{0}\right)$ to the maximal $\left(\mathrm{F}_{\mathrm{M}}\right)$ fluorescence value, which have been labeled as O-step $(20 \mu \mathrm{s})$, J-step (2 ms), I-step (30 ms), and P-step (0.5-1 s) (Strauss et al. 2006). The leaves were dark-adapted for at least $30 \mathrm{~min}$ before measurements. For each treatment, 12 plants were randomly selected for measurement. The transients in leaves were induced by red light (peak at $650 \mathrm{~nm}$ ) of 3,000 $\mu \mathrm{mol}$ (photon) $\mathrm{m}^{-2} \mathrm{~s}^{-1}$ provided by an array of three light-emitting diodes. The fluorescence signal induced between $10 \mathrm{~s}$ and $1 \mathrm{~s}$ is received by the sensor head and is digitized in the control unit using a fast digital converter. Original fluorescence transients were transferred with the professional $P E A$ Plus and Biolyzer HP3 software to a spreadsheet. The JIP-test defines the maximal (subscript ' 0 ') energy fluxes in the energy cascade for the events absorption (ABS), trapping $\left(\mathrm{TR}_{0}\right)$, electron transport $\left(\mathrm{ET}_{0}\right)$, and reduction of end acceptors $\left(\mathrm{RE}_{0}\right)$. PSII behavior was characterized on the basis of several parameters derived from the OJIP transients, which are based on the Theory of Energy Fluxes in Biomembranes (Strasser 1981). Therefore, the definitions and equations of the JIP-test are shown in Fig. 1S (supplement) by using a scheme (modified after Tsimilli-Michael and Strasser 2008), which is the wellknown Z-scheme of photosynthesis. The energy fluxes and energy bifurcations (wide arrows) represent the outfluxes for energy conservation (grey arrows) and the outfluxes for dissipation (white arrows), respectively. Further details of formulae and glossary of terms used by the JIP-test are listed in Table 1S (supplement). 
Transmission electron microscopy (TEM) analysis: Fresh unfolded leaf tissues ( $\left.c a .2 \mathrm{~mm}^{2}\right)$ of rice seedlings were fixed in $1 \%(\mathrm{v} / \mathrm{v})$ glutaraldehyde for $3 \mathrm{~d}$ at $4^{\circ} \mathrm{C}$. Samples were postfixed in $1 \%(\mathrm{v} / \mathrm{v})$ osmium tetraoxide for $2 \mathrm{~h}$ at $4{ }^{\circ} \mathrm{C}$ followed by dehydration in a gradient series of increasing acetone concentrations. Then, the dehydrated samples were progressively embedded in Epon-araldite, followed by polymerization in the resin. Ultrathin sections (about $80 \mathrm{~nm}$ ) were prepared and mounted on 300-mesh coated copper grids for staining with uranyl acetate for $30 \mathrm{~min}$ and lead citrate for $7 \mathrm{~min}$ and finally examined using a Hitachi 600A-2 transmission electron microscope.

Isolation of intact chloroplasts: Intact chloroplasts were isolated according to the method of Seigneurin-Berny et al. (2008) with a slight modification. Briefly, leaves (15 g) were homogenized at $4^{\circ} \mathrm{C}$ with $30 \mathrm{ml}$ of $2 \mathrm{mM}$ ascorbate, $30 \mathrm{mM}$ MES, $330 \mathrm{mM}$ sorbitol, and $0.1 \%$ BSA (w/v), adjusted to $\mathrm{pH} 6.5$ with Tris. The homogenate was filtered through four layers of skim gauze and centrifuged at $1,500 \times g$ for $5 \mathrm{~min}$. The precipitations were resuspended in $3 \mathrm{ml}$ of suspension buffer $(330 \mathrm{mM}$ sorbitol, $30 \mathrm{mM}$ Hepes and $0.2 \%$ BSA, adjusted to $\mathrm{pH} 7.5$ with Tris), then put into a tube containing $10 \mathrm{ml}$ of chloroplast resuspension medium in 40/80\% Percoll, and horizontally centrifuged for $20 \mathrm{~min}$ at $3,000 \times \mathrm{g}$. The intact chloroplasts were located at the interlayer between 40 and $80 \%$ Percoll, and washed twice by suspension buffer after aspiration in order to remove Percoll followed by centrifugation at $12,000 \times g$ for $10 \mathrm{~min}$. All procedures were carried out at $4^{\circ} \mathrm{C}$. The chloroplast pellets were resuspended in icecold resuspension buffer containing $272 \mathrm{mM}$ sucrose, $40 \mathrm{mM}$ Hepes ( $\mathrm{pH} 7.5)$ and $150 \mathrm{mM} \mathrm{KCl}$, and adjusted to the equal Chl concentration. The intactness of chloroplasts was about $80 \%$ according to the method of Aravind and Prasad (2004).

Blue native-polyacrylamide gel electrophoresis (BNPAGE): The supernatant enriched with chloroplasts was supplemented with an equal volume of $2 \%$ n-dodecyl- $\beta$-dmaltoside (DM) in a dark ice bath for $45 \mathrm{~min}$. After 15-min centrifugation with $16,000 \times g$ at $4^{\circ} \mathrm{C}$, the supernatant was supplemented with $1 / 10$ volume of $5 \%$ Serva Blue $G$ [100 mM Bis-Tris-HCl (pH 7.0), 0.5 M 6-amino-n-caproic acid, and $30 \%$ glycerol], and subjected to BN-PAGE according to the method described by Schägger and von Jagow (1991). The equal volumes of supernatant equivalent to $8 \mu \mathrm{g}(\mathrm{Chl})$ were subjected to BN-PAGE with a linear gradient of $5-12 \%(\mathrm{w} / \mathrm{v})$ acrylamide and a stacking gel of $4.5 \%(\mathrm{w} / \mathrm{v})$ acrylamide. Electrophoresis was carried out at $4^{\circ} \mathrm{C}$, set at $80 \mathrm{~V}$ until the proteins had entered the stacking gel, and then set to $180 \mathrm{~V}$ for approximately $3 \mathrm{~h}$. The BN-gels stained with $0.025 \%$ (w/v) Serva Blue $G$ were scanned and the optical density along each lane was analyzed by quantitation software (Quantify One, Bio-Rad, USA).

ROS production and lipid peroxidation in chloroplasts: Superoxide radical $\left(\mathrm{O}_{2}{ }^{-}\right)$content was determined by using the method of Elstner and Heupel (1976) with a minor modification. The chloroplast supernatants $(0.2 \mathrm{ml})$ were mixed with $0.75 \mathrm{ml}$ of $65 \mathrm{mM}$ phosphate buffer solution ( $\mathrm{pH} 7.8$ ) and $0.05 \mathrm{ml}$ of $10 \mathrm{mM}$ hydroxylamine hydrochloride for incubation at $25^{\circ} \mathrm{C}$ for $30 \mathrm{~min}$. Then, the mixture was mixed with $1 \mathrm{ml}$ of $17 \mathrm{mM}$ sulfanilamide and $1 \mathrm{ml}$ of $7 \mathrm{mM} \alpha$-naphthylamine, and again incubated at $25^{\circ} \mathrm{C}$ for $20 \mathrm{~min}$. The absorbance was measured at $530 \mathrm{~nm}$ (GENESYS 10, Thermo Electron, USA). $\mathrm{O}_{2}{ }^{--}$generation rate was calculated by using a standard curve of $\mathrm{NaNO}_{2}$.

Hydrogen peroxide $\left(\mathrm{H}_{2} \mathrm{O}_{2}\right)$ concentration was determined according to $\mathrm{Yu}$ et al. (2003) with a minor modification. The chloroplast supernatant $(0.2 \mathrm{ml})$ was added to $2 \mathrm{ml}$ of a mixture of $0.1 \% \mathrm{TiCl}_{4}$ in $20 \% \mathrm{H}_{2} \mathrm{SO}_{4}(\mathrm{v} / \mathrm{v})$ and centrifuged at $6,000 \times g$ for $15 \mathrm{~min}$. The supernatants were spectrophotometrically (GENESYS 10, Thermo Electron, USA) measured at $410 \mathrm{~nm}$ and calculated by using a standard curve of $\mathrm{H}_{2} \mathrm{O}_{2}$.

Lipid peroxidation was estimated by determining the concentration of malondialdehyde (MDA) produced by thiobarbituric acid (TBA) reaction according to method of Kramer et al. (1991). The chloroplast supernatant (0.5 ml) reacted with $2 \mathrm{ml}$ of $0.5 \%$ thiobarbituric acid in $20 \%$ TCA, followed by boiling at $95^{\circ} \mathrm{C}$ for $30 \mathrm{~min}$, and the reaction was stopped in ice bath. The samples were centrifuged at $12,000 \times g$ for $10 \mathrm{~min}$, followed by determination of absorbance at 440, 532, and $600 \mathrm{~nm}$.

Antioxidant enzyme activities in chloroplasts: Equal amounts of chloroplasts, by Chl concentration, were added to extract buffer consisting of $25 \mathrm{mM}$ Hepes buffer ( $\mathrm{pH} 7.8$ ), $0.2 \mathrm{mM}$ EDTA, and 2\% PVP (w/v). The supernatants were used for antioxidant enzyme activity determination after centrifugation.

Superoxide dismutase (SOD, EC 1.15.1.1) activity was assayed by quantifying the photoreduction of nitroblue tetrazolium (NBT) according to the method described by Panda et al. (2017) with slight modifications. Reaction was performed using a reaction mixture consisting of $50 \mathrm{mM}$ phosphate buffer ( $\mathrm{pH} 7.8$ ), $13 \mathrm{mM}$ methionine, $0.1 \mathrm{mM}$ EDTA-Na $2,50 \mathrm{mM}$ sodium carbonate, $9.9 \mathrm{mM}$ NBT, $2.4 \mathrm{mM}$ riboflavin, and $0.05 \mathrm{ml}$ of enzyme extract. The absorbance was measured at $560 \mathrm{~nm}$, and one unit of enzyme activity was taken as that amount of enzyme that inhibits the reduction of NBT by $50 \%$.

Catalase (CAT, EC 1.11.1.6) activity was measured as the decrease in absorbance at $240 \mathrm{~nm}$ that accompanied the consumption of $\mathrm{H}_{2} \mathrm{O}_{2}$ (Panda et al. 2017). The reaction mixture consisted of $1 \mathrm{ml} 0.3 \% \mathrm{H}_{2} \mathrm{O}_{2}, 1.95 \mathrm{ml}$ of $\mathrm{H}_{2} \mathrm{O}$, and $0.05 \mathrm{ml}$ of enzyme extract. The activity was calculated using the extinction coefficient $(\varepsilon)$ of $43.6 \mathrm{M}^{-1} \mathrm{~cm}^{-1}$ at $240 \mathrm{~nm}$.

Ascorbate peroxidase (APX, EC 1.11.1.11) activity was measured by recording the change in absorbance at $290 \mathrm{~nm}$ as described by Jin et al. (2008). The reaction was carried out using a reaction mixture including $50 \mathrm{mM}$ phosphate buffer ( $\mathrm{pH} 7.0$ ), $0.5 \mathrm{mM}$ ascorbic acid, $0.1 \mathrm{mM}$ $\mathrm{H}_{2} \mathrm{O}_{2}$, and $0.05 \mathrm{ml}$ enzyme extract. The activity of APX was determined by the decrease in the absorbance at $290 \mathrm{~nm}$ and the amount of ascorbate oxidized using extinction coefficient $(\varepsilon)$ of $2.8 \mathrm{mM}^{-1} \mathrm{~cm}^{-1}$ at $290 \mathrm{~nm}$.

Glutathione reductase (GR, EC 1.6.4.2) activity was estimated by measuring the rate of reduction of 5,5'- 
dithiobis-(2-nitrobenzoic acid) (DTNB) as an increase in absorbance at $412 \mathrm{~nm}\left(\varepsilon=14.15 \mathrm{mM}^{-1} \mathrm{~cm}^{-1}\right)$ according to the procedure described in Panda et al. (2017).

For CAT, APX, and GR, one unit of enzyme was defined as the amount of enzyme necessary to decompose $1 \mu \mathrm{mol}$ of substrate per minute at $25^{\circ} \mathrm{C}$.

Statistical analysis: All experiments were carried out in at least three biological replications. The means and standard deviations (SD) were calculated using SPSS 17.0 and a Tukey's HSD multiple range test at a significance level of $P<0.05$.

\section{Results}

Apparent injury and photosynthetic pigments: Salt stress caused severe inhibition of plant growth characteristics (Fig. 1A). The leaves of rice seedlings were dehydrated and shriveled upon $\mathrm{NaCl}$ treatment, while Spd amendment to the salt-treated plants decreased the area and the degree of shrinkage; only the edges of leaves exhibited curling. There was a slight increase but no significant difference in the photosynthetic pigment contents of rice seedlings supplemented with Spd under nonsalinity conditions (Fig. $1 B-E$ ). Compared with control, salt stress caused reduction of $\mathrm{Chl} a(45.1 \%)$, Chl $b(32.2 \%)$, total Chl (44.2\%), and Chl $a / b(19.0 \%)$. However, a positive effect of Spd was observed in rice seedlings after 7-d treatment with the high concentration of $\mathrm{NaCl}$; $\mathrm{Chl} a$, $\mathrm{Chl} b$, total Chl, and Chl $a / b$ increased by $33.0,13.1,27.7$, and $17.6 \%$, respectively.

Chl $\boldsymbol{a}$ fluorescence transients of the dark-adapted leaves of rice seedlings under different treatments were shown, on logarithmic time scale from $10 \mu$ s up to $1 \mathrm{~s}$, in Fig. $2 A$. The following phenomena can be observed from fluorescence transient OJIP curves: (1) all curves showed the typical OJIP shape consisting of O-, J-, I-, P-steps; (2) with the $\mathrm{NaCl}$ treatment, K-step appeared, the major change was an increase in the J-step and a decrease in I-P phase; (3) maximum fluorescence $\left(\mathrm{F}_{\mathrm{M}}\right)$ went down and minimum fluorescence $\left(\mathrm{F}_{0}\right)$ remained constant; (4) treatment with Spd significantly increased the intensity of fluorescence in the OJIP transient under salt stress. The insert in Fig. $2 A$ presents the relative variable fluorescence curves normalized by $\mathrm{F}_{0}$ and $\mathrm{F}_{\mathrm{M}}$ : $\left[\mathrm{V}_{\mathrm{t}}=\right.$ $\left.\left(F_{t}-F_{0}\right) /\left(F_{M}-F_{0}\right)\right]$. Obviously, the values of $V_{K}$ and $V_{J}$ significantly increased during the exposure to salt stress, and markedly declined by adding exogenous Spd.

Each transient depicted in Fig. $2 A$ can be analyzed by the JIP-test to yield structural and functional parameters quantitating PSII behavior and activity, and the kinetics of PSII electron flow reactions (Fig. $2 B$ ). As the spider plot shows in Fig. $2 B$, we observed that the maximum quantum yield of primary photochemistry $\left(\varphi_{\mathrm{P} 0}\right)$ values changed little under different treatments. In contrast to $\varphi_{\mathrm{P} 0}$,

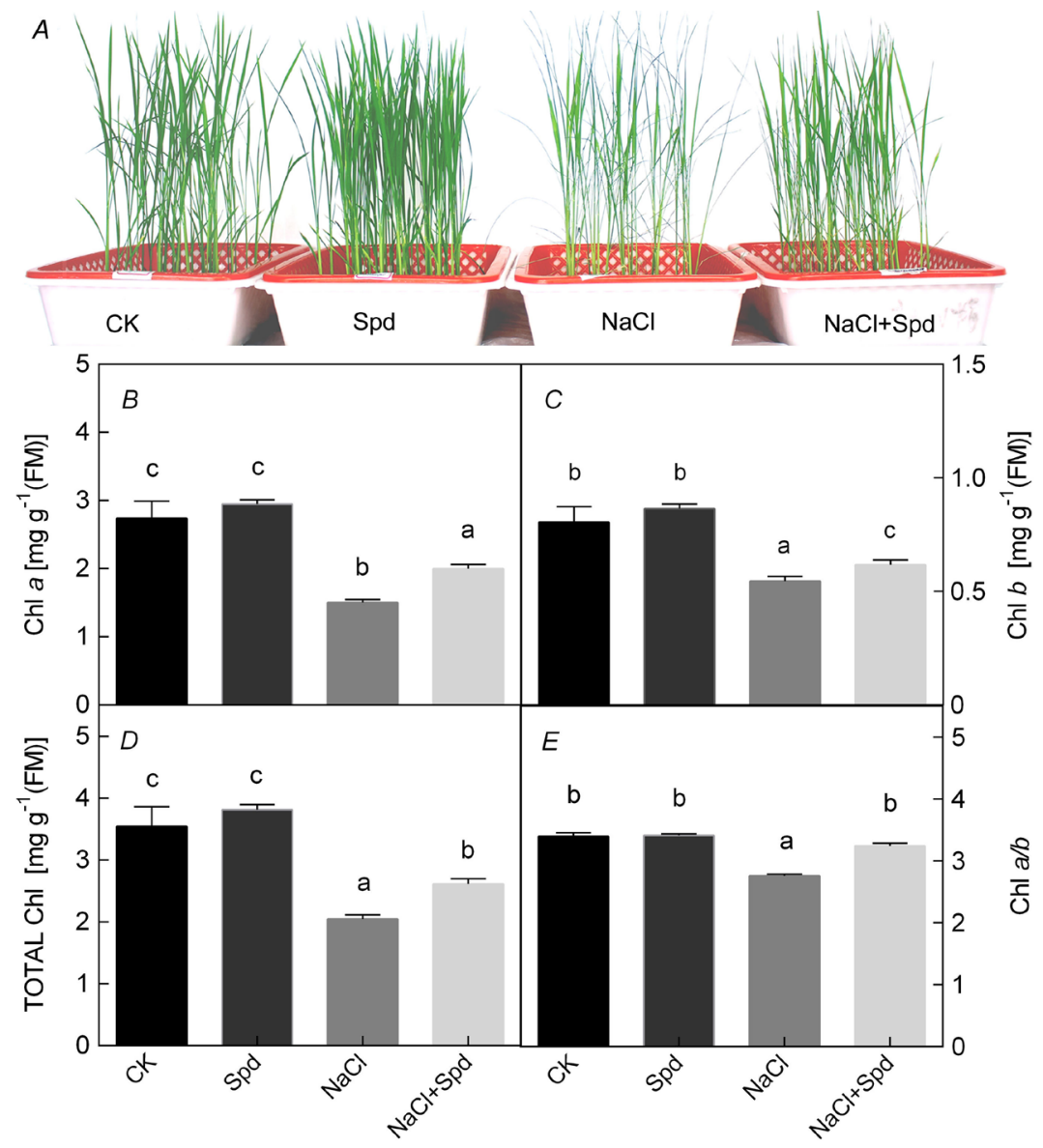

Fig. 1. Effect of exogenous spermidine (Spd) on growth performance and chlorophyll $(\mathrm{Chl})$ content of rice seedlings. $(A)$ growth performance of rice seedlings; $(B) \mathrm{Chl} a$; (C) Chl $b ;(D)$ total Chl; $(E) \mathrm{Chl} a / b$ ratio. Values are means $\pm \mathrm{SD}(n=6)$. Different lowercase letters above the error bars denote significant differences at $P \leq 0.05$. 
A

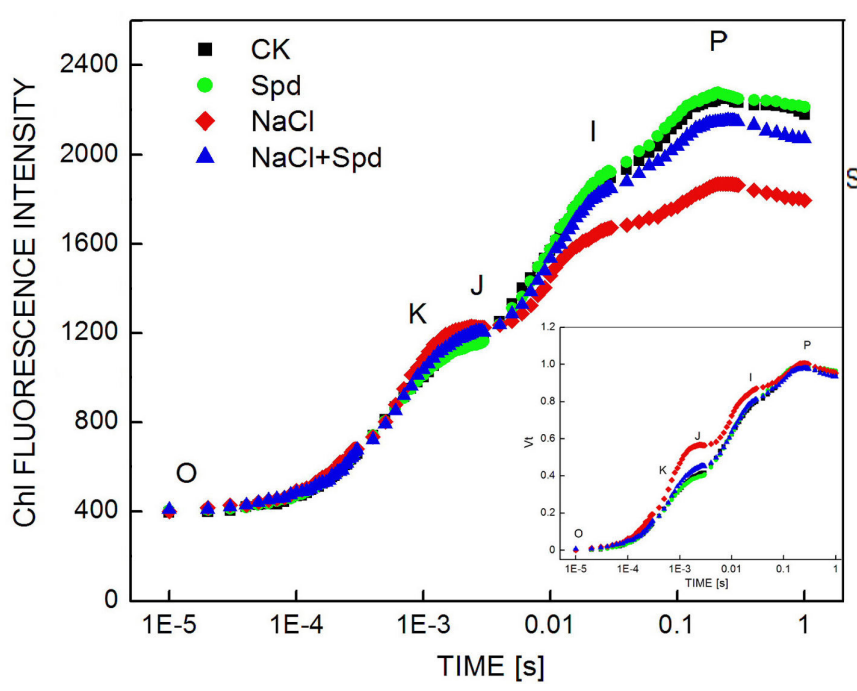

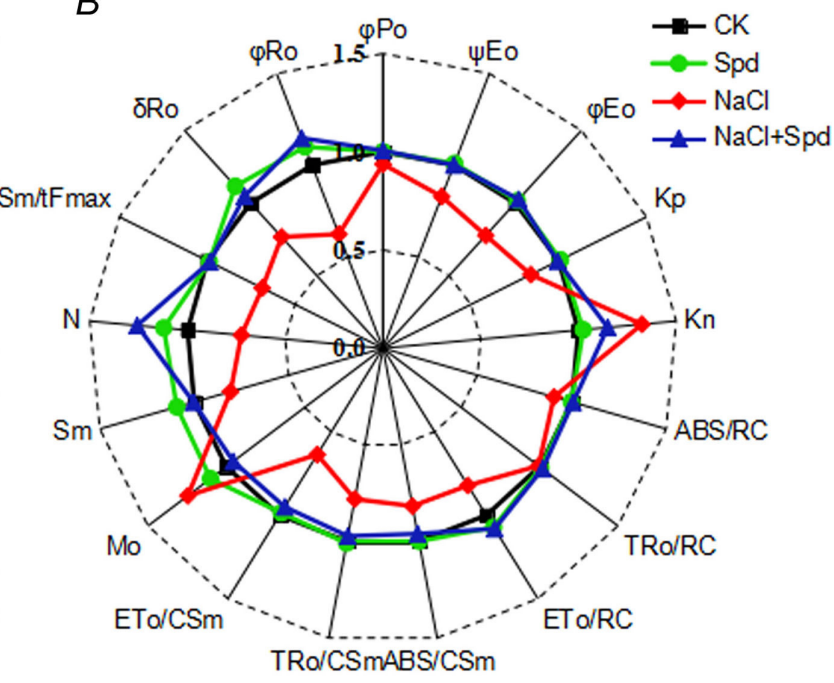

Fig. 2. Effect of exogenous spermidine (Spd) on chlorophyll fluorescence of rice seedlings. $(A)$ raw curves without any normalization and curves normalized by $\mathrm{F}_{0}$ and $\mathrm{F}_{\mathrm{M}}\left[\mathrm{V}_{\mathrm{t}}=\left(\mathrm{F}_{\mathrm{t}}-\mathrm{F}_{0}\right) /\left(\mathrm{F}_{\mathrm{M}}-\mathrm{F}_{0}\right)\right]$ in the insert. $(B)$ structural and functional photosynthetic parameters (average values of 12 replicates) derived by the JIP-test from the fluorescence transients. For each parameter, values were normalized by using as reference the control (untreated) plants, presented in the panel by squares (all parameters equal to unity). $\mathrm{O}$ indicates the $\mathrm{O}$-step at about $20 \mu \mathrm{s}$; K indicates the K-step at about $300 \mu \mathrm{s}$; J indicates the J-step at about $2 \mathrm{~ms}$; I indicates the I-step at about $30 \mathrm{~ms}$; $\mathrm{P}$ indicates the P-step, the maximum fluorescence. All results are the averages of 12 biological replicates. As indicated, black, green, red, blue colors (symbols) refer to different groups and correspond to untreated (CK, squares) and those treated with $1 \mathrm{mM}$ spermidine (Spd, circles), $100 \mathrm{mM} \mathrm{NaCl}(\mathrm{NaCl}$, diamonds) or $100 \mathrm{mM} \mathrm{NaCl}$ and $1 \mathrm{mM}$ spermidine $(\mathrm{NaCl}+\mathrm{Spd}$, triangles), respectively.

the probability to move an electron further than $\mathrm{Q}_{\mathrm{A}}^{-}\left(\psi_{\mathrm{E} 0}\right)$, quantum yield for electron transport $\left(\varphi_{\mathrm{E} 0}\right)$, the probability to reduce an end electron acceptor $\left(\delta_{\mathrm{R} 0}\right)$, and quantum yield for reduction of end electron acceptors at the PSI acceptor side $\left(\varphi_{\mathrm{R} 0}\right)$ decreased strongly under salt stress, whereas the application of exogenous Spd alleviated the decline of these parameters dramatically. The parameters referring to the sequential energy transduction include the energy fluxes for (light) absorption (ABS), trapping $\left(\mathrm{TR}_{0}\right)$, and electron transport $\left(\mathrm{ET}_{0}\right)$. These parameters are expressed per $\mathrm{CS}_{\mathrm{m}}$ (cross section) or per RC (reaction center). The energy fluxes per RC are functional parameters (specific energy fluxes), while the energy fluxes per $\mathrm{CS}_{\mathrm{m}}$ express the corresponding quantum yields and are structural parameters. Under the salinity conditions, $\mathrm{ET}_{0} / \mathrm{RC}, \mathrm{ABS} / \mathrm{CS}_{\mathrm{m}}$, $\mathrm{TR}_{0} / \mathrm{CS}_{\mathrm{m}}$, and $\mathrm{ET}_{0} / \mathrm{CS}_{\mathrm{m}}$ decreased strongly, but no visible changes in $\mathrm{ABS} / \mathrm{RC}$ and $\mathrm{TR}_{0} / \mathrm{RC}$ occurred. Compared with CK-treated seedlings, those subjected to salt stress exhibited significantly reduced photochemical rate constant $\left(\mathrm{K}_{\mathrm{p}}\right)$ and increased nonphotochemical rate constant $\left(\mathrm{K}_{\mathrm{n}}\right)$. However, all these negative effects caused by salt stress could be effectively eliminated by adding exogenous Spd. Compared with the control, rice seedlings subjected to $\mathrm{NaCl}$ treament exhibited significantly increased initial slope $\left(\mathrm{M}_{0}\right)$ expressing the net rate of $\mathrm{Q}_{\mathrm{A}}$ reduction or the RC closure, while adding Spd decreased it (Fig. 2). After salt stress, the $S_{m}$ value used to quantify multiple-turnover $\mathrm{Q}_{\mathrm{A}}$ reduction events decreased by $20 \%$ relative to the control. Meanwhile, total turnover number of $\mathrm{Q}_{\mathrm{A}}$ reduction events $(N)$ showed a similar trend to $S_{m}$. However, application of exogenous Spd significantly increased the values of $\mathrm{S}_{\mathrm{m}}$ and $\mathrm{N}$ of plants with $\mathrm{NaCl}$ (increased by 24.3 and $73.6 \%$, respectively). $\mathrm{S}_{\mathrm{m}} / \mathrm{t}_{\mathrm{Fmax}}$ significantly declined in plants treated only with $\mathrm{NaCl}$, which confirmed the severe closure of PSII RCs induced by $\mathrm{NaCl}$. The presence of Spd counteracted the effect of salt stress, and $\mathrm{S}_{\mathrm{m}} / \mathrm{t}_{\mathrm{Fmax}}$ value returned to normal levels.

Functional indexes: Fig. 3 showed the effect of Spd on the PSII behaviors, quantified by the performance index $\left(\mathrm{PI}_{\text {total }}\right)$ presented with four components $[\mathrm{RC} / \mathrm{ABS}$, $\left.\varphi_{\mathrm{P} 0} /\left(1-\varphi_{\mathrm{P} 0}\right), \varphi_{\mathrm{E} 0} /\left(1-\varphi_{\mathrm{E} 0}\right), \delta_{\mathrm{R} 0} /\left(1-\delta_{\mathrm{R} 0}\right)\right]$. The log of $\mathrm{PI}_{\text {total }}$ was expressed as $\mathrm{DF}_{\text {total }}$ called driving force. Furthermore, the product of these four independent parameters is also used as expression of the structure function index for photosynthetic systems $\left(\mathrm{SFI}_{\text {total }}\right)$. Under nonsalinity conditions, the value of $\mathrm{PI}_{\text {total }}$ significantly improved by $29.6 \%$ with adding exogenous Spd. Under salt stress, $\mathrm{PI}_{\text {total }}$ decreased to $77.9 \%$ that of control, while exogenous Spd strongly relieved the decline of $\mathrm{PI}_{\text {total }}$. Parameters $\mathrm{SFI}_{\text {total }}$ and $\mathrm{DF}_{\text {total }}$ showed the similar trend as that of $\mathrm{PI}_{\text {total }}$.

Ultrastructure of chloroplasts: No significant changes occurred in ultrastructure of chloroplasts and thylakoids of rice seedlings between the control and Spd-treated plants as shown by TEM (Fig. 4A,B). The chloroplasts in two groups were of characteristic flat elliptical shape and thylakoids were regularly arranged. Small and rarely found osmiophilic plastoglobuli were presented in these chloroplasts. In contrast to the control, the chloroplasts in salt-stressed plants appeared as seriously distorted and separated from the plasma membrane (Fig. 4C). 


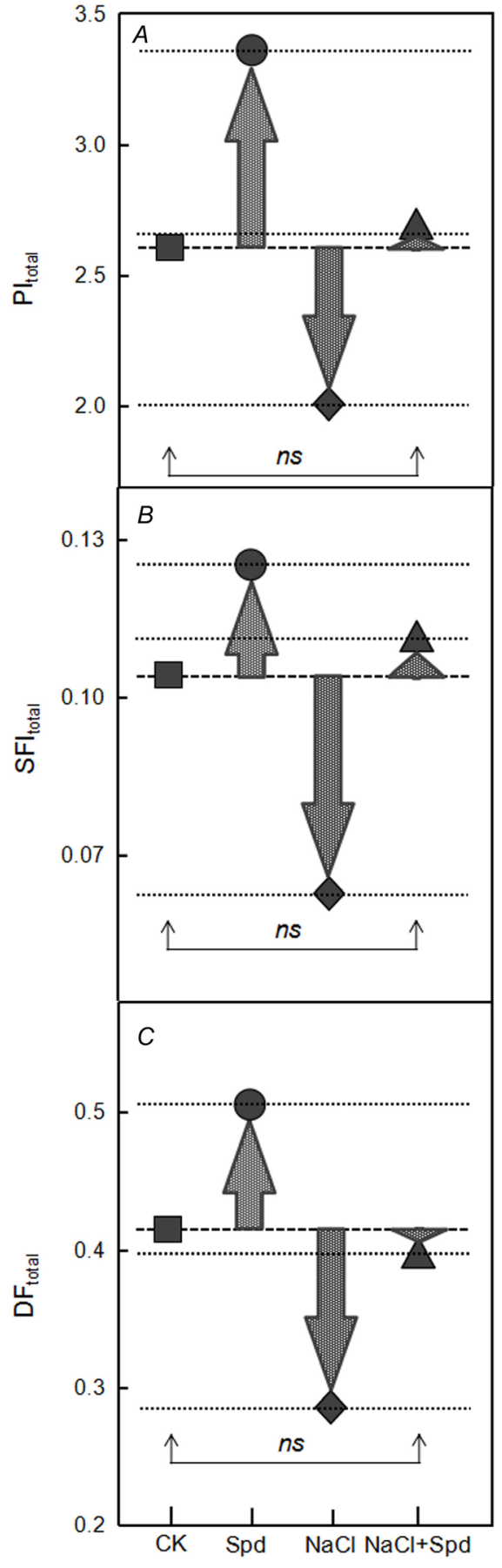

Fig. 3. Effect of exogenous spermidine (Spd) on functional indexes of rice leaves. $(A) \mathrm{PI}_{\text {total }}$, performance index; $(B) \mathrm{SFI}_{\text {total }}$, structure function index for photosynthetic systems; $(C) \mathrm{DF}_{\text {total }}$, driving force on absorption basis. These performance parameters were derived by the JIP-test from chlorophyll fluorescence transients (shown in Fig. $2 A$ ) of dark-adapted leaves from rice seedlings that were either untreated (squares), or treated with $1 \mathrm{mM}$ spermidine (circles), $100 \mathrm{mM} \mathrm{NaCl}$ (diamonds) or 100 $\mathrm{mM} \mathrm{NaCl}+1 \mathrm{mM}$ spermidine (triangles). Downwards arrows indicate the loss, while upwards arrows indicate the gain. The values are means of 12 replicates; all the differences except those marked as 'ns' (not significant) are statistically significant $(P<0.05)$.
The internal structure in chloroplasts showed a severe dilation of the thylakoid membranes and dismantling of grana stacks, leaving diffuse membranes and numerous osmiophilic plastoglobuli. Nevertheless, the amount and organization of thylakoids in the chloroplasts of plants under salt stress treated with Spd differed remarkably (Fig. 4D). Exogenous Spd alleviated the structural changes of chloroplasts and thylakoid membranes induced by salt stress. The chloroplasts still maintained several tightly packed grana stacks consisted of at least ten thylakoids and contained less osmiophilic plastoglobuli.

Thylakoid membrane protein complexes: To confirm the chloroplast integrity and further investigate the specific changes in thylakoid membrane, we performed a BN gel separation. We observed five distinct major bands representing the PSI supercomplexes and PSII supercomplexes (PSI SC, PSII SC), PSI monomers, and PSII dimers (PSI-M, PSII-D), PSII monomers, and cytochrome $b_{6} / f$ complexes (PSII-M, Cyt $\left.b_{6} / f\right)$, PSII LHC trimers (LHCII-T), and PSII LHC monomers (LHCII-M) (Fig. 5A). The optical density along each lane was quantified by Quantify One software and their relative contents were calculated (Fig. 5B). Except for LHCII-M, no significant differences in thylakoid membrane protein complexes between the control and Spd treated plants were found. However, amounts of PSII SC and PSI SC, PSI-M and PSII-D, PSII-M, and Cyt $b_{6} / f$, and LHCII-T (reduced by $35.4,53.0,42.1$, and 55.6\%, respectively) decreased under

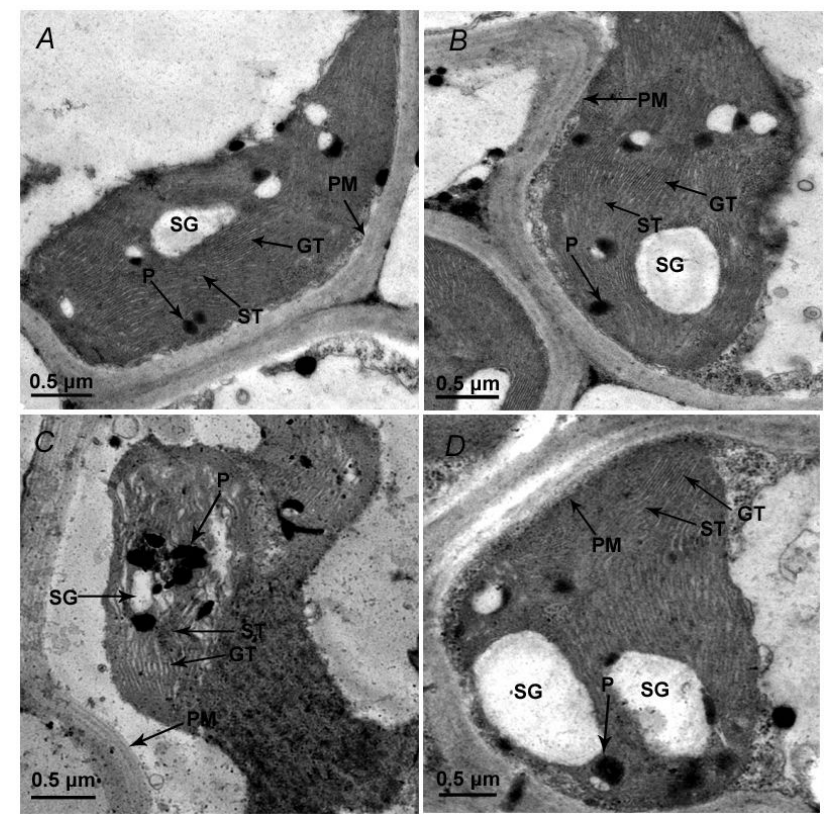

Fig. 4. Effect of exogenous spermidine (Spd) on the ultrastructure of chloroplasts and thylakoids of rice seedlings. $(A) \mathrm{CK}, 0 \mathrm{mM}$ $\mathrm{NaCl}+0 \mathrm{mM}$ spermidine; $(B) \mathrm{Spd}, 0 \mathrm{mM} \mathrm{NaCl}+1 \mathrm{mM} \mathrm{Spd}$; (C) $\mathrm{NaCl}, 100 \mathrm{mM} \mathrm{NaCl}+0 \mathrm{mM} \mathrm{Spd}$ (D) $\mathrm{NaCl}+\mathrm{Spd}$, $100 \mathrm{mM} \mathrm{NaCl}+1 \mathrm{mM} \mathrm{Spd}$. The fourth fully expanded leaves of two groups were sampled for ultramicroscopic observation after 7-day treatment. ST - stromal thylakoid; GT - grana thylakoid; $\mathrm{SG}$ - starch grain; P - plastoglobule; PM - plasma membrane. 
$\mathrm{NaCl}$-induced salt stress, while increased (1.25-, 2.01-, $1.36-$, and 1.97-fold, respectively) by adding exogenous Spd. Hence, Chl-pigment complexes were stable in Spdtreated leaves during salt stress.

ROS production and lipid peroxidation in chloroplasts: $\mathrm{NaCl}$ stress caused a significant increase in the contents of $\mathrm{O}_{2}{ }^{-}(315.4 \%), \mathrm{H}_{2} \mathrm{O}_{2}(152.5 \%)$, and MDA (361.4\%), as compared with the controls (Fig. 6). Application of Spd alone did not notably affect ROS production and MDA content in the chloroplasts of rice seedlings; however, addition of Spd with the $100 \mathrm{mM} \mathrm{NaCl}$ prevented the effects of $\mathrm{NaCl}$ alone. These results indicated that exogenous $\mathrm{Spd}$ mitigated membrane lipid peroxidation in chloroplasts and partially alleviated the suppressed growth.

Antioxidant enzymes in chloroplasts: SOD, CAT, APX, and GR were the enzymes selected to assess the oxidative damage caused by salt stress. In general, treatment with Spd alone increased the activities of the antioxidant enzymes assayed, especially the GR activity was enhanced by $45.7 \%$ by Spd (Fig. 7). Compared with the CK, the activities of SOD, APX, and GR significantly increased (Fig. 7A,C,D) under salt stress, except for the CAT activity inhibited by $48.9 \%$ (Fig. $7 B$ ). After application of Spd, we observed that exogenous Spd further increased the activities of SOD, APX, and GR, and mitigated the activity of CAT inhibited by salinity.

\section{Discussion}

Supplementation with Spd has been shown to attenuate various abiotic stresses in plants including Cucumis sativus, Zoysia japonica, Avena sativa, Oryza sativa, and Malus sieversii (Besford et al. 1993, Chattopadhayay et al. 2002 , Liu et al. 2008, Roychoudhury et al. 2011, Shu et al. 2013, Li et al. 2016). Nevertheless, our knowledge regarding the mechanisms involved in Spd-mediated tolerance to salt stress still remains fragmentary. In the present study, we confirmed that addition of Spd had a protective role on the photosynthetic apparatus of rice seedlings exposed to high salt conditions.

Salt stress often led to unfavorable effects on the growth and Chl metabolisms of plants (Mittal et al. 2012, Li et al. 2015a, Jin et al. 2019). It is well known that Chl $b$ is formed from Chl $a$ by the oxidation of the methyl group on ring II of the aldehyde. As the first step of Chl degradation, the conversion of $\mathrm{Chl} a$ to $\mathrm{Chl} b$ also influences the $\mathrm{Chl} a / b$ ratio. In the present study, the dehydration and withering status in leaves of the $100 \mathrm{mM} \mathrm{NaCl}$-treated seedlings significantly reversed when supplied with exogenous Spd (Fig. 1A). This was consistent with previous studies (Roychoudhury et al. 2011). Substantial enhancement of photosynthetic pigment contents occurred in Spd-treated plants under salt stress (Fig. $1 B-E$ ). In addition, Spd strongly increased the $\mathrm{Chl} a / b$ ratio, indicating that $\mathrm{Spd}$ effectively prevented the loss of Chl $a$ and maintained the photosynthetic performance of seedlings under salt stress, because high Chl $a$ as the pigment of the RCs is more conducive to plant light energy conversion and photosynthetic efficiency (Farquhar and Sharkey 1982). Our results strongly confirmed the beneficial effect of Spd on the Chl content of rice seedlings under salt stress, especially on the Chl $a$ content.

The intricate relationships between fluorescence kinetics and photosynthesis are very convenient and straightforward for us to understand the changes in photosynthetic biophysical processes during plant responses
A

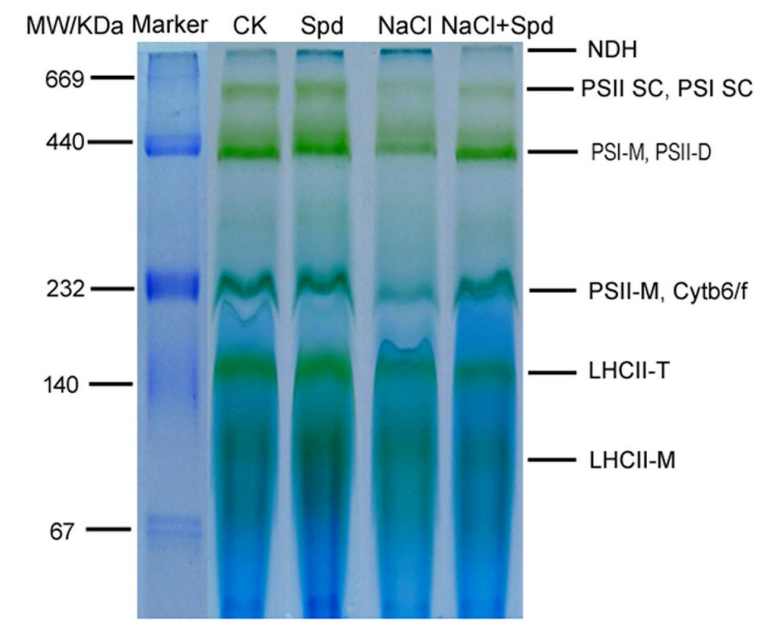

B

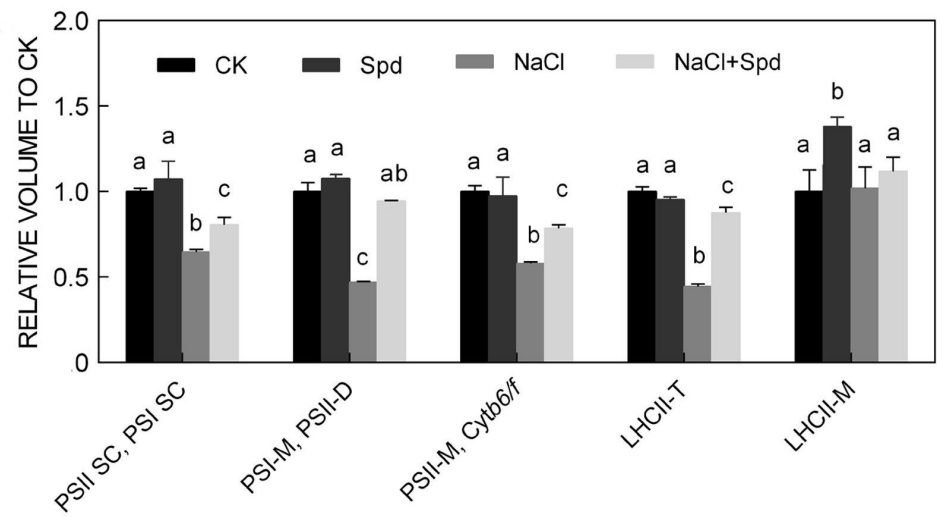

Fig. 5. Effect of exogenous Spd on thylakoid membrane protein complexes of rice seedlings. $(A)$ Distribution of thylakoid membrane protein complexes $(8 \mu \mathrm{g}$ chlorophylls) separated by BN-PAGE. Molecular mass (MW) of marker was labeled on the left and the nomenclature of the resolved bands was on the right. $(B)$ Quantitation of thylakoid membrane protein complexes. The BN-gels were scanned and the optical density along each lane was quantified (Quantify One, Bio-Rad, USA). For each thylakoid membrane protein complex, values were normalized by using as reference the control (untreated) plants (all parameters equal to unity). Values are means \pm SD $(n=3)$. LHCII-M - PSII LHC monomers; LHCII-T - PSII LHC trimers; NDH - NADPH dehydrogenase complexes; PSI-M - PSI monomers; PSI SC - PSI supercomplexes; PSII SC - PSII supercomplexes; PSII-M - PSII monomers; PSII-D - PSII dimers; Cyt $b_{6} / f$ - cytochrome $b_{6} / f$ complexes. 


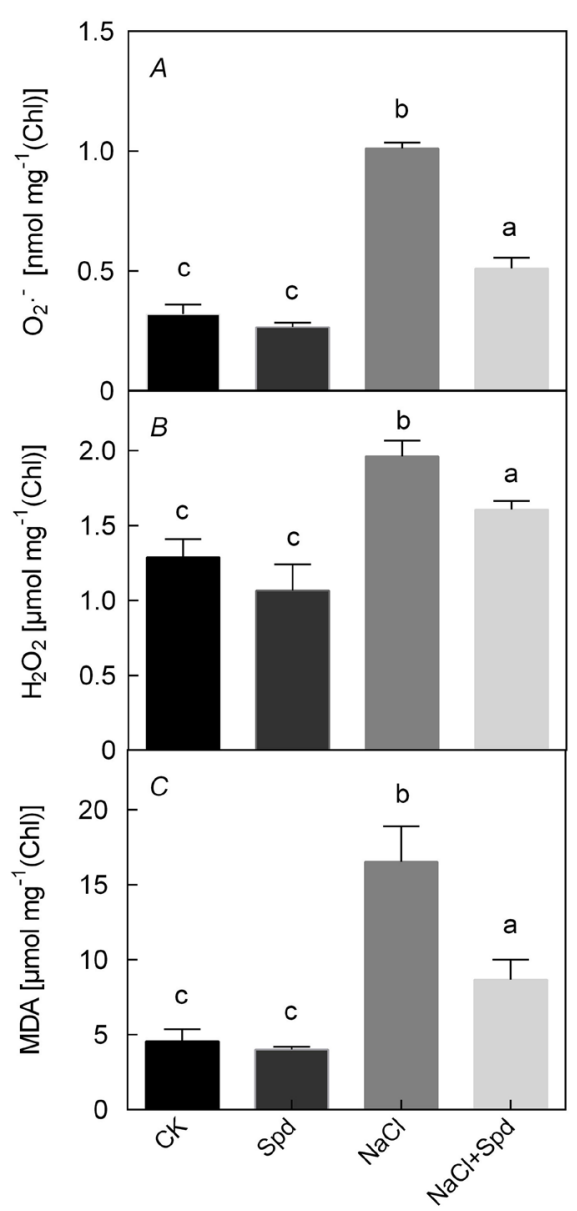

Fig. 6. Effect of exogenous spermidine (Spd) on reactive oxygen species and lipid peroxidation in chloroplasts of rice seedlings. (A) $\mathrm{O}_{2}{ }^{--}$, superoxide radical; $(B) \mathrm{H}_{2} \mathrm{O}_{2}$, hydrogen peroxide; (C) MDA, malondialdehyde. Values are means $\pm \mathrm{SD}(n=3)$. Different lowercase letters above the error bars denote significant differences at $P \leq 0.05$.

to environmental stress (Sayed 2003). In this study, salt stress-induced damage to PSII photochemistry was demonstrated by the Chl $a$ fluorescence kinetics (Fig. 2A). Single-turnover events with respect to $\mathrm{Q}_{\mathrm{A}}$ reduction mainly occur in O-J phase (Strasser 1981, Strauss et al. 2006). Therefore, compared with the CK, a strong increase of the $\mathrm{J}$ level in stressed group reflected the accumulation of $\mathrm{Q}_{\mathrm{A}^{-}}$, which was also the evidence for the damage in PSII donor side and electron transfer chain (Fig. 2A). Although $\mathrm{NaCl}$ did not significantly change the $\mathrm{F}_{0}$, a distinct decrease in $F_{V}$ and $F_{M}$ indicated the lower ability of PSII to reduce the primary acceptor $\mathrm{Q}_{\mathrm{A}}$. The drop in the area formed $v s$. time between the $\mathrm{F}_{\mathrm{I}}$ and $\mathrm{F}_{\mathrm{M}}$ of the I-P phase manifested the decline in the size of the terminal electron acceptor pool. Obviously, the levels of $\mathrm{V}_{\mathrm{K}}$ and $\mathrm{V}_{\mathrm{J}}$ significantly increased during the exposure to salt stress, which suggested that $\mathrm{NaCl}$ treatment could result in an inhibition of oxygenevolving complex (OEC) and a fast accumulation of $\mathrm{Q}_{\mathrm{A}}^{-}$ in PSII RCs (Strasser et al. 1995, Lazár 2006). However, these negative impacts were markedly alleviated by applying exogenous Spd. PSII behavior/activity was characterized on the basis of several parameters derived from the OJIP-transients, which are based on the Theory of Energy Fluxes in Biomembranes (Strasser 1981, Strasser et al. 1995, Sayed 2003). In this study, salt stress induced the reduction of $\varphi_{\mathrm{E} 0}$ and $\psi_{\mathrm{E} 0}$, which reflected the decrease in electron transfer rate on the PSII acceptor side (Fig. 2B). Additionally, $\mathrm{V}_{\mathrm{J}}$ and $\mathrm{M}_{0}$ increased significantly under salt stress, further demonstrating the fact that electrons transferred from $\mathrm{Q}_{\mathrm{A}}$ to $\mathrm{Q}_{\mathrm{B}}$ on the PSII acceptor side were blocked. Notably, excess activation energy generated by the blockade of electron transfer may be converted into ROS, causing the oxidative damage to thylakoid membrane (Fig. 5). We also observed the drop in the absorption energy flux per RC or per excited cross section (ABS/RC, ABS/ $\mathrm{CS}_{\mathrm{m}}$ ) under salt stress, suggesting PSII antenna pigments were damaged. There was no significant difference in trapping energy flux per $\mathrm{RC}\left(\mathrm{TR}_{0} / \mathrm{RC}\right)$, while the electron transport flux $\left(\mathrm{ET}_{0} / \mathrm{RC}\right)$ decreased notably. Furthermore, salt stress also significantly decreased the energy fluxes per excited cross section $\left(\mathrm{TR}_{0} / \mathrm{CS}_{\mathrm{m}}\right.$ and $\left.\mathrm{ET}_{0} / \mathrm{CS}_{\mathrm{m}}\right)$, which may be attributed to the decrease of PSII active RCs per excited cross section $\left(\mathrm{RC} / \mathrm{CS}_{\mathrm{m}}\right)$. The decreases of $\mathrm{V}_{\mathrm{J}}$ and $\mathrm{M}_{0}$, and the increases of $\varphi_{\mathrm{E} 0}, \psi_{\mathrm{E} 0}, \mathrm{ABS} / \mathrm{RC}, \mathrm{ET}_{0} / \mathrm{RC}, \mathrm{ABS} / \mathrm{CS}_{\mathrm{m}}$, $\mathrm{TR}_{0} / \mathrm{CS}_{\mathrm{m}}$, and $\mathrm{ET}_{0} / \mathrm{CS}_{\mathrm{m}}$ in exogenously Spd-treated plants indicated that Spd effectively maintained the stability of the electron transport chain and the activity of PSII.

The performance index $\left(\mathrm{PI}_{\text {total }}\right)$ is one of the most sensitive indicators to various stress conditions (TsimilliMichael and Strasser 2008). We observed that Spd enhanced the salinity resistance of rice seedlings by increasing the decreases of $\mathrm{PI}_{\text {total }}, \mathrm{DF}_{\text {total }}$, and $\mathrm{SFI}_{\text {total }}$ caused by $\mathrm{NaCl}$ (Fig. 3). The increases in these parameters indicated that Spd had the ability to alleviate the adverse effect of salinity on the PSII structure, function, and activity. $\mathrm{PI}_{\text {total }}$ and $\mathrm{SFI}_{\text {total }}$ are produced by the four independent components RC/ABS, $\varphi_{\mathrm{P} 0}, \varphi_{\mathrm{E} 0}$, and $\delta_{\mathrm{R} 0}$ (Tsimilli-Michael and Strasser 2008). $\mathrm{NaCl}$ mainly acted on $\varphi_{\mathrm{E} 0}$ and $\delta_{\mathrm{R} 0}$, not on $\varphi_{\mathrm{P} 0}$ or RC/ABS, suggesting that the most direct cause of the decrease in $\mathrm{PI}_{\text {total }}$ and $\mathrm{SFI}_{\text {total }}$ was the rapid decrease in the efficiency of electron transfer redox reactions (Fig. 2B). This assumption may obtain further support from results concerning the decline of electron transport $\left(\mathrm{ET}_{0} / \mathrm{RC}\right.$ and $\left.\mathrm{ET}_{0} / \mathrm{CS}_{\mathrm{m}}\right)$, a strong decrease of $\mathrm{K}_{\mathrm{p}}$, and a significant increase of $\mathrm{K}_{\mathrm{n}}$ in comparison to control. From JIP-test, the decline in $\mathrm{S}_{\mathrm{m}}$ and $\mathrm{N}$ caused by salt stress led to a large accumulation of $\mathrm{Q}_{\mathrm{A}^{-}}$, which inhibited PSII RCs activities. $\mathrm{S}_{\mathrm{m}} / \mathrm{t}_{\mathrm{Fmax}}$ (the average redox state of the redox couple $\mathrm{Q}_{\mathrm{A}}{ }^{-} / \mathrm{Q}_{\mathrm{A}}$ ) significantly declined in plants treated only with $\mathrm{NaCl}$, meaning that $\mathrm{NaCl}$ caused the severe closure of PSII RCs. When treated with exogenous $\mathrm{Spd}$, the significant increase in $\mathrm{S}_{\mathrm{m}} / \mathrm{t}_{\mathrm{Fmax}}$ indicated that Spd could effectively alleviate the closure of PSII RCs. Maintaining structural and functional organization of chloroplasts is vital for the dynamics and flexibility of the photosynthetic apparatus. Photosystems involve Chl and pigment-protein complexes located in thylakoids. Therefore, a proper state of thylakoids is critical for stabilizing the function and efficiency of photosystems (Zhang et al. 2010). In this study, we detected the degradation of thylakoid membranes with the accumulation of plastoglobuli under 


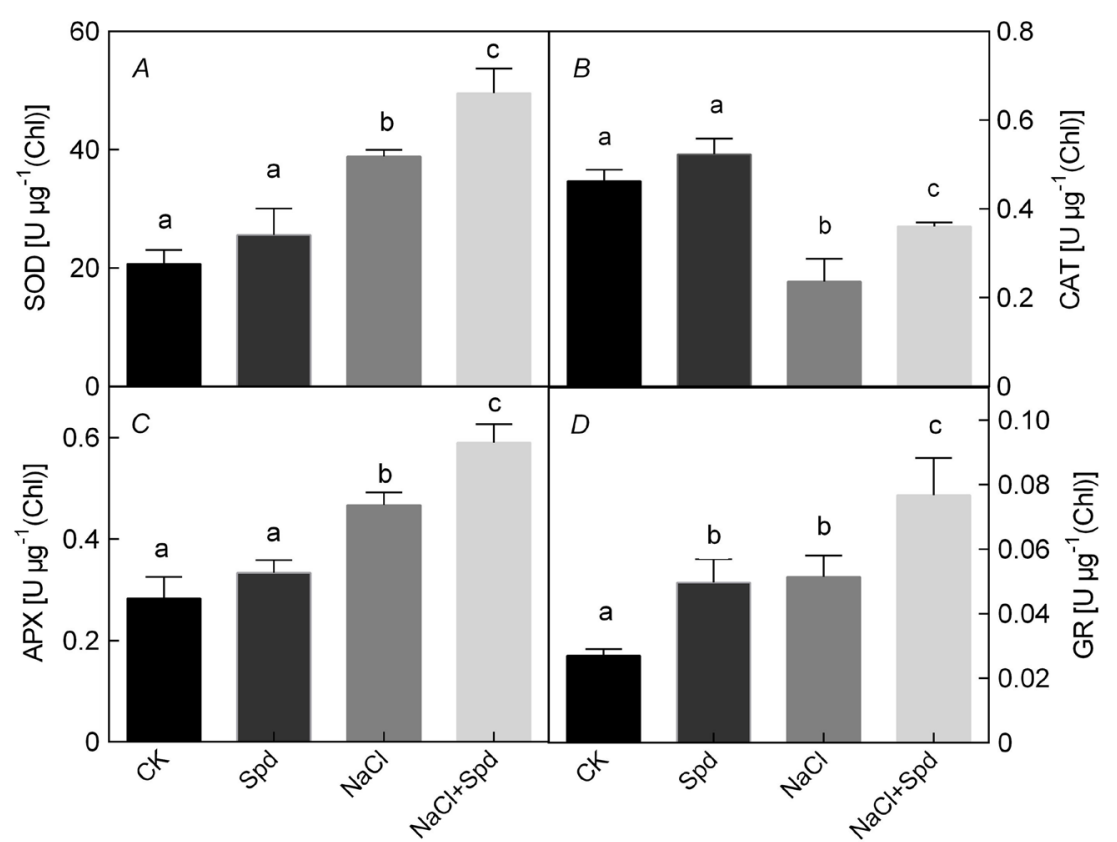

Fig. 7. Effect of exogenous Spd on antioxidant enzyme activities in chloroplasts of rice seedlings. $(A) \mathrm{SOD}$, superoxide dismutase; (B) CAT, catalase; $(C)$ APX, ascorbate peroxidase; $(D)$ GR, glutathione reductase. Values are means $\pm \mathrm{SD}(n=3)$. Different lowercase letters above the error bars denote significant differences at $P \leq 0.05$. salt stress (Fig. 4C), which was generally attributed to lipid peroxidation-mediated membrane damage. By contrast, the stressed rice seedlings treated with exogenous Spd showed less osmiophilic plastoglobuli and more grana consisting of numerous tightly packed thylakoids in chloroplasts (Fig. 4D). Many studies have focused on $\mathrm{Chl}$ and protein degradation during chloroplast breakdown (Hörtensteiner et al. 2009). We found that major thylakoid membrane protein complexes strongly decreased under salt stress (Fig. 5), while the addition of Spd prevented it. Photosystem supercomplexes, especially PSII supercomplexes as well as its two components, LHCII trimers and PSII dimers (Nelson and Yocum 2006), were significantly promoted by Spd, indicating that Spd had a significant positive effect on maintaining the integrity of the PSII structure and supported the capture and transport of light energy. Furthermore, Cyt $b_{6} / f$ also increased under the action of exogenous Spd during salt stress, which was consistent with the higher transmission capacity of electron transfer chain (Fig. 2). Notably, content of Chl and amount of thylakoid membrane protein complexes increased by applying Spd, which may be attributed to the covalent binding of Spd to thylakoid membrane proteins to stabilize the thylakoid membrane structure or enhance the repair process of thylakoid membrane components (Dondini et al. 2003).

When plants are exposed to environmental stresses, loss of PSII activity causes the block of electrons in the electron transport chain, leading to an imbalance between energy production and utilization. Therefore, excess electrons are converted into ROS, such as singlet oxygen $\left({ }^{1} \mathrm{O}_{2}\right), \mathrm{O}_{2}{ }^{-}, \mathrm{OH} \cdot$, and $\mathrm{H}_{2} \mathrm{O}_{2}$ in chloroplasts (Asada 2006). In turn, the overproduction of ROS can result in the damage of PSII activity by inducing the degradation of pigmentprotein complexes and inhibiting the repair process of PSII (Allakhverdiev et al. 2008). ROS are primarily derived from chloroplasts, which can trigger the thylakoid membrane lipid peroxidation by ${ }^{1} \mathrm{O}_{2}$ or oxygen reduction (Sharma et al. 2012). Therefore, MDA, membrane lipid peroxidation product, can substantially act as an important reflection of membrane injury caused by oxidative stress (Anjum et al. 2012). In the present study, we found that salt stress induced the accumulation of $\mathrm{H}_{2} \mathrm{O}_{2}$ and $\mathrm{O}_{2}{ }^{-}$in rice chloroplasts (Fig. 6A,B). Meanwhile, MDA significantly increased under salt stress compared to normal conditions (Fig. 6C), demonstrating that ROS overproduction was responsible for the damage of thylakoid membrane induced by salt stress.

The plants have an intrinsic mechanism that comprises of enzymatic antioxidative system to counter the salinityinduced oxidative stress triggered by the overproduction of ROS. Previous studies have reported that Spd confers salinity tolerance in plants through synthesizing antioxidant metabolites, activating antioxidant enzymes, or/and affecting the activities of enzymes involved in PA metabolism to counter the salinity induced oxidative stress triggered by the excess ROS (Kuznetsov et al. 2006, Li et al. 2015a,b). As revealed in the present study, SOD, APX, and GR activities increased significantly in $\mathrm{NaCl}$ or $\mathrm{NaCl}+$ Spd-treated plants with respect to the control (Fig. 7). Among all the antioxidant enzymes, SOD acts as a primary defense enzyme scavenging $\mathrm{O}_{2}{ }^{-}$radical. SOD initiates detoxification of $\mathrm{O}_{2}^{-}$by forming $\mathrm{H}_{2} \mathrm{O}_{2}$, which is also toxic and is eliminated by conversion to $\mathrm{H}_{2} \mathrm{O}$ in the subsequent reactions through a number of enzymes, such as CAT, APX, and GR. Although CAT activity in chloroplasts was significantly inhibited by salinity, it greatly increased by application of Spd (Fig. 7B). As two key enzymes in the ASA-GSH cycle, APX and GR play a central role in the regulation of the intracellular redox balance (Mittler 2002). In this cycle, AsA is catalyzed by APX to form monodehydroascorbate by consuming $\mathrm{H}_{2} \mathrm{O}_{2}$, and GSSG is reduced by GR to form GSH (Apel and Hirt 2004). In the present study, both APX and GR 
activities dramatically increased by exposure to $\mathrm{NaCl}+$ Spd treatment, in comparison to $\mathrm{NaCl}$ treatment alone (Fig. $7 C, D$ ). In addition, GSH may help stabilize enzymes of the Calvin cycle (Bradbeer 1969), which could explain that plants treated with Spd exhibited much higher biomass (Fig. 1) and showed better photosynthetic performance than that of controls (Fig. 3). These results indicated that Spd-dependent reduction of the oxidative stress caused by salinity was closely related to the induction of antioxidant enzyme activities in chloroplasts. Obviously, the application of exogenous Spd efficiently reduced ROS accumulation and lipid peroxidation levels in chloroplasts by enhancing antioxidant enzyme system, which ensured a better photosynthetic environment and increased plant tolerance to salt stress.

Conclusions: Generally, exogenous Spd treatment had significantly beneficial effects on $\mathrm{NaCl}$-exposed rice seedlings and effectively alleviated $\mathrm{NaCl}$-induced damage of chloroplasts. The lowered contents of supercomplexes, PSII RCs, PSII LHC, and Cyt $b_{6} / f$ in thylakoid membranes under salt stress were promoted by applying Spd, which concomitantly improved photosynthetic pigment contents and photosynthetic performance of rice seedlings. Exogenous Spd successfully prevented salt stress which would otherwise induce the accumulation of ROS and MDA in chloroplasts. Notably, the elevated SOD, CAT, APX, and GR activities in chloroplasts play a vital role in Spdinduced alleviation of oxidative stress. Furthermore, Spd could enhance the repair process of thylakoid membranes under salt stress, conferring higher oxidative stress tolerance to rice chloroplasts.

\section{References}

Allakhverdiev S.I., Kreslavski V.D., Klimov V.V. et al.: Heat stress: an overview of molecular responses in photosynthesis.Photosynth. Res. 98: 541-550, 2008.

Anjum S.A., Saleem M.F., Wang L.C. et al.: Protective role of glycinebetaine in maize against drought-induced lipid peroxidation by enhancing capacity of antioxidative system. Aust. J. Crop Sci. 6: 576-583, 2012.

Apel K., Hirt H.: Reactive oxygen species: metabolism, oxidative stress, and signal transduction. - Annu. Rev. Plant Biol. 55: 373-399, 2004.

Aravind P., Prasad M.N.V.: Zinc protects chloroplasts and associated photochemical functions in cadmium exposed Ceratophyllum demersum L., a fresh water macrophyte. Plant Sci. 166: 1321-1327, 2004.

Asada K.: Production and scavenging of reactive oxygen species in chloroplasts and their functions. - Plant Physiol. 141: 391-396, 2006.

Beauchemin R., Gauthier A., Harnois J. et al.: Spermine and spermidine inhibition of photosystem II: disassembly of the oxygen evolving complex and consequent perturbation in electron donation from TyrZ to $\mathrm{P} 680^{+}$and the quinone acceptors $\mathrm{Q}_{\mathrm{A}}{ }^{-}$to $\mathrm{Q}_{\mathrm{B}}$. - BBA-Bioenergetics 1767: 905-912, 2007.

Beigbeder A., Vavadakis M., Navakoudis E., Kotzabasis K.: Influence of polyamine inhibitors on light-independent and light-dependent chlorophyll biosynthesis and on the photosynthetic rate. - J. Photoch. Photobio. B 28: 235-242,
1995.

Besford R.T., Richardson C.M., Campos J.L., Tiburcio A.F.: Effect of polyamines on stabilization of molecular complexes in thylakoid membranes of osmotically stressed oat leaves. Planta 189: 201-206, 1993.

Bradbeer J.W.: The activities of the photosynthetic carbon cycle enzymes of greening bean leaves. -New Phytol. 68: 233-245, 1969.

Chattopadhayay M.K., Tiwari B.S., Chattopadhayay G. et al.: Protective role of exogenous polyamines on salinity-stressed rice (Oryza sativa) plants. - Physiol. Plantarum 116: 192-199, 2002.

Dondini L., Del Duca S., Dall'Agata L. et al.: Suborganellar localization and effect of light on Helianthus tuberosus chloroplast transglutaminases and their substrates. - Planta 217: 84-95, 2003.

Duan J.J., Li J., Guo S.R., Kang Y.Y.: Exogenous spermidine affects polyamine metabolism in salinity-stressed Cucumis sativus roots and enhances short-term salinity tolerance. J. Plant Physiol. 165: 1620-1635, 2008.

Elstner E.F., Heupel A.: Inhibition of nitrate formation from hydroxylammonium chloride: a simple assay for superoxide dismutase. - Anal. Biochem. 70: 616-620, 1976.

Farquhar D.G., Sharkey T.D.: Stomatal conductance and photosynthesis. - Ann. Rev. Plant Physio. 33: 317-345, 1982.

Gil R., Boscaiu M., Lull C. et al.: Are soluble carbohydrates ecologically relevant for salt tolerance in halophytes? - Funct. Plant Biol. 40: 805-818, 2013.

He L.X., Nada K., Kasukabe Y., Tachibana S.: Enhanced susceptibility of photosynthesis to low-temperature photoinhibition due to interruption of chill-induced increase of S-adenosylmethionine decarboxylase activity in leaves of spinach (Spinacia oleracea L.). - Plant Cell Physiol. 43: 196-206, 2002.

Hörtensteiner S.: Stay-green regulates chlorophyll and chorophyll-binding protein degradation during senescence. Trends Plant Sci. 14: 155-162, 2009.

Igarashi K., Kashiwagi K.: Polyamines: Mysterious modulators of cellular functions. - Biochem. Bioph. Res. Co. 271: 559564,2000

Jin X.F., Yang X., Islam E. et al.: Effects of cadmium on ultrastructure and antioxidative defense system in hyperaccumulator and non-hyperaccumulator ecotypes of Sedum alfredii Hance. - J. Hazard. Mater. 156: 387-397, 2008.

Jin X.Q., Liu T., Xu J.J. et al.: Exogenous GABA enhances muskmelon tolerance to salinity-alkalinity stress by regulating redox balance and chlorophyll biosynthesis. - BMC Plant Biol. 19: 48, 2019.

Kaiser E., Morales A., Harbinson J. et al.: Dynamic photosynthesis in different environmental conditions. - J. Exp. Bot. 66: 24152426, 2015.

Kasukabe Y., He L.X., Nada K. et al.: Overexpression of spermidine synthase enhances tolerance to multiple environmental stresses and up-regulates the expression of various stress regulated genes in transgenic Arabidopsis thaliana. Plant Cell Physiol. 45: 712-722, 2004.

Kotzabasis K., Fotinou C., Roubelakis-Angelakis K.A., Ghanotakis D.: Polyamines in the photosynthetic apparatus: Photosystem II highly resolved subcomplexes are enriched in spermine. - Photosynth. Res. 38: 83-88, 1993.

Kramer G.F., Norman H.A., Krizek D.T., Mirecki R.M.: Influence of UV-B radiation on polyamines, lipid peroxidation and membrane lipids in cucumber. - Phytochemistry 30: 21012108, 1991.

Kuznetsov V.V., Radyukina N.L., Shevyakova N.I.: Polyamines and stress: Biological role, metabolism, and regulation. - 
Russ. J. Plant Physl+ 53: 583-604, 2006.

Lazár D.: The polyphasic chlorophyll $a$ fluorescence rise measured under high intensity of exciting light. - Funct. Plant Biol. 33: 9-30, 2006.

Li J.M., Hu L.P., Zhang L. et al.: Exogenous spermidine is enhancing tomato tolerance to salinity-alkalinity stress by regulating chloroplast antioxidant system and chlorophyll metabolism. - BMC Plant Biol. 15: 303, 2015a.

Li S.C., Jin H., Zhang Q.: The Effect of exogenous spermidine concentration on polyamine metabolism and salt tolerance in zoysiagrass (Zoysia japonica Steud) subjected to short-term salinity stress. - Front. Plant Sci. 7: 1221, 2016.

Li Z., Zhou H., Peng Y. et al.: Exogenously applied spermidine improves drought tolerance in creeping bentgrass associated with changes in antioxidant defense, endogenous polyamines and phytohormones. - Plant Growth Regul. 76: 71-82, 2015b.

Lichtenthaler H.K.: Chlorophylls and carotenoids: Pigments of photosynthetic biomembranes. - Method. Enzymol. 148: 350-382, 1987.

Liu J.H., Inoue H., Moriguchi T.: Salt stress-mediated changes in free polyamine titers and expression of genes responsible for polyamine biosynthesis of apple in vitro shoots. - Environ. Exp. Bot. 62: 28-35, 2008.

Mittal S., Kumari N., Sharma V.: Differential response of salt stress on Brassica juncea: Photosynthetic performance, pigment, proline, D1 and antioxidant enzymes. - Plant Physiol. Bioch. 54: 17-26, 2012.

Mittler R.: Oxidative stress, antioxidants and stress tolerance. Trends Plant Sci. 7: 405-410, 2002.

Munns R., Tester M: Mechanisms of salinity tolerance. - Annu. Rev. Plant Biol. 59: 651-681, 2008.

Navakoudis E., Vrentzou K., Kotzabasis K.: A polyamineand LHCII protease activity-based mechanism regulates the plasticity and adaptation status of the photosynthetic apparatus. - BBA-Bioenergetics 1767: 261-271, 2007.

Nelson N., Yocum C.F.: Structure and function of photosystems I and II. - Annu. Rev. Plant Biol. 57: 521-565, 2006.

Noctor G., Foyer C.H.: Ascorbate and glutathione: Keeping active oxygen under control. - Annu. Rev. Plant Phys. 49: 249-279, 1998.

Pál M., Szalai G., Janda T.: Speculation: Polyamines are important in abiotic stress signaling. - Plant Sci. 237: 16-23, 2015.

Panda A., Rangani J., Kumari A., Parida A.K.: Efficient regulation of arsenic translocation to shoot tissue and modulation of phytochelatin levels and antioxidative defense system confers salinity and arsenic tolerance in the halophyte Suaeda maritima. - Environ. Exp. Bot. 143: 149-171, 2017.

Roychoudhury A., Basu S., Sengupta D.N.: Amelioration of salinity stress by exogenously applied spermidine or spermine in three varieties of indica rice differing in their level of salt tolerance. - J. Plant Physiol. 168: 317-328, 2011.

Sayed O.H.: Chlorophyll fluorescence as a tool in cereal crop research. - Photosynthetica 41: 321-330, 2003.

Schägger H., von Jagow G.: Blue native electrophoresis for isolation of membrane protein complexes in enzymatically active form. - Anal. Biochem. 199: 223-231, 1991.

Seigneurin-Berny D., Salvi D., Dorne A.J. et al.: Percoll-purified and photosynthetically active chloroplasts from Arabidopsis thaliana leaves. - Plant Physiol. Bioch. 46: 951-955, 2008.

Sharma P., Jha A.B., Dubey R.S., Pessarakli M.: Reactive oxygen species, oxidative damage, and antioxidative defense mechanism in plants under stressful conditions. - J. Bot. 2012: 217037, 2012.

Shu S., Yuan L.Y., Guo S.R. et al.: Effects of exogenous spermine on chlorophyll fluorescence, antioxidant system and ultrastructure of chloroplasts in Cucumis sativus L. under salt stress. - Plant Physiol. Bioch. 63: 209-216, 2013.

Strasser R.J.: The grouping model of plant photosynthesis: Heterogeneity of photosynthetic units in thylakoids. In: Akoyunoglou G. (ed.): Photosynthesis III. Structure and Molecular Organisation of the Photosynthetic Apparatus. Pp. 727-737. Balaban International Science Services, Philadelphia 1981.

Strasser R.J., Srivastava A., Govindjee: Polyphasic chlorophyll a fluorescence transient in plants and cyanobacteria. Photochem. Photobiol. 61: 342, 1995.

Strauss A.J., Krüger G.H.J., Strasser R.J., Van Heerden P.D.R.: Ranking of dark chilling tolerance in soybean genotypes probed by the chlorophyll $a$ fluorescence transient O-J-I-P. Environ. Exp. Bot. 56: 147-157, 2006.

Tsimilli-Michael M., Strasser R.J.: In vivo assessment of stress impact on plants' vitality: Applications in detecting and evaluating the beneficial role of mycorrhization on host plants. - In: Varma A. (ed.): Mycorrhiza. State of the Art, Genetics and Molecular Biology, Eco-Function, Biotechnology, Eco-Physiology, Structure and Systematics. $3^{\text {rd }}$ Edition. Pp. 679-703. Springer, Berlin-Heidelberg 2008.

Watanabe S., Kusama-Eguchi K., Kobayashi H., Igarashi K.: Estimation of polyamine binding to macromolecules and ATP in bovine lymphocytes and rat liver.- J. Biol. Chem. 266: 20803-20809, 1991.

Yu C.W., Murphy T.M., Lin C.H.: Hydrogen peroxide-induces chilling tolerance in mung beans mediated through ABAindependent glutathione accumulation. - Funct. Plant Biol. 30: 955-963, 2003.

Zhang M.P., Zhang C.J, Yua G.H. et al.: Changes in chloroplast ultrastructure, fatty acid components of thylakoid membrane and chlorophyll $a$ fluorescence transient in flag leaves of a super-high-yield hybrid rice and its parents during the reproductive stage. - J. Plant Physiol. 167: 277-285, 2010.

(C) The authors. This is an open access article distributed under the terms of the Creative Commons BY-NC-ND Licence. 